\title{
A aplicabilidade dos conceitos bourdieunianos de habitus e campo em uma pesquisa na área da História da Educação
}

Pablo Silva Machado Bispo dos Santos Doutorando em Educação - PUC-Rio; Professor do Curso de Pedagogia da Universidade Estácio de Sá. Rio de Janeiro - RJ [Brasil] pablo.santos@docente.estacio.br
Pretendemos, neste trabalho, analisar a operacionalidade de dois conceitos criados por Pierre Bourdieu, com alcance de amplo espectro, para o trabalho de pesquisa em ciências sociais (BOURDIEU, 2004). Trata-se dos conceitos de habitus e campo, concebidos pelo eminente sociólogo francês como verdadeiras ferramentas operacionais de suporte ao trabalho de pesquisa. Nesse sentido, cabe mencionar que buscamos explorar algumas das possibilidades de utilização desses conceitos em uma pesquisa histórica, posto que sua versatilidade, em termos de riqueza conceitual, extrapola os limites da Sociologia, podendo ser empregados também em outros campos das Ciências Sociais, como a História, e, mais precisamente, a história da Educação. Este trabalho é composto das seguintes partes: a) Breve explanação dos conceitos de habitus e campo; b) A aplicabilidade dos conceitos em uma pesquisa no campo da história da Educação; c) Considerações finais.

Palavras-chave: Campo. Habitus. História da Educação.

Pesquisa. Sociologia da educação. 


\section{Introdução}

História e Sociologia são dois campos que, em muitos casos, alimentam-se mutuamente. Autores como Fernand Braudel e Marc Ferro, já nos anos de 1970, propunham uma aproximação entre esses dois campos disciplinares, de forma que ambos pudessem se enriquecer mutuamente e, ao mesmo tempo, produzir achados científicos mais rigorosos (REVEL, 2001). No que se refere à História e à Sociologia da Educação, essa proximidade se mostra ainda maior, pois ambas estudam o mesmo objeto: a educação. Tomando como base essa premissa, buscamos explorar as possibilidades de explicação/ compreensão de dois conceitos criados no campo da Sociologia: de habitus e de campo, de autoria de Pierre Bourdieu.

\section{Breve explanação do conceito de habitus e de campo}

Antes de iniciarmos a discussão, enfoque principal neste trabalho, ou seja, a aplicabilidade do conceito de habitus e de campo em uma pesquisa na área da história da Educação, cabe situar o leitor na perspectiva teórica adotada como referência. Assim, segue abaixo breve explanação de tais conceitos.

Segundo Bourdieu (2001), o babitus consiste em uma matriz geradora de comportamentos, visões de mundo e sistemas de classificação da realidade que se incorporam aos indivíduos (ao mesmo tempo que se desenvolvem neles), seja no nível das práticas, seja no da postura corporal (hexis) desses mesmos sujeitos. Desse modo, o babitus é apreendido e gerado na sociedade e incorporado pelos indivíduos. Pode-se afirmar, indubitavelmente, que o habitus sofre o efeito das transformações ocorridas na cultura e na sociedade, mas também influencia essas mesmas mudanças por consistir em uma espécie de segunda natureza (PASCAL, 2000) dos indivíduos, acoplada à sua subjetividade mais profunda e consciente, mas não totalmente subsumida por essa dimensão racional, e que gera hábitos e ações nem sempre explicáveis pelas vias da lógica formal. Para ilustrar o que isso implica, eis a seguinte citação de Pierre Bourdieu: “[...] o conceito de habitus tem por função primordial lembrar com ênfase que nossas ações possuem freqüentemente, por princípio, mais o senso prático do que o cálculo racional" (BOURDIEU, 2003, p. 78). Concordamos com Setton (2002, p. 61) quando afirma que "[...] embora seja visto como um sistema gerado no passado e orientando para uma ação no presente, ainda é um sistema em constante reformulação. Habitus não é destino." Nesse sentido, cabe pensar nessa "segunda natureza", acoplada à subjetividade e à racionalidade individual como uma espécie de matriz intermediária entre o sujeito e as estruturas sociais. Em decorrência desse caráter flexível e relacional, o conceito de habitus somente pode ser entendido com o seu "par lógico" (e epistemológico): o conceito de campo.

Esse conceito complementa o de habitus, pois, para Bourdieu (2001), o campo consiste no espaço em que ocorrem as relações entre os indivíduos, grupos e estruturas sociais, com uma dinâmica que obedece a leis próprias, animadas sempre pelas disputas ocorridas em seu interior, e cujo móvel é invariavelmente o interesse em ser bem-sucedido nas relações estabelecidas entre os seus componentes (seja no nível dos agentes, seja no nível das estruturas). A esse interesse, Bourdieu denomina illusio, expressão latina que designa

Dialogia, São Paulo, v. 6, p. 49-54, 2007. 
uma forma particular de interesse, o de estar envolvido no jogo (BOURDIEU, 2003). No que se refere ao alcance e à abrangência desse conceito, cabe indicar que o campo possui uma forma variável, segundo o tipo de sociedade em que se situa, o que corresponderia às relações próprias entre as diferentes estruturas e agentes, de acordo com cada caso. Desse modo, cada campo possui uma lógica que lhe é própria ${ }^{1}$. Assim, o campo estabelece, ainda, uma relação direta com os homens, na medida em que sua configuração específica se consubstancia na estrutura formativa do habitus dos indivíduos presentes no campo, pois, conforme já afirmado, o babitus tem a propriedade de fazer com que o indivíduo incorpore propriedades relativas à lógica do(s) campo(s) a que se encontra exposto em sua trajetória social.

\section{A aplicabilidade do conceito de habitus de campo em uma pesquisa no âmbito da história da Educação}

O conceito de habitus e de campo se caracterizam, entre outras coisas, por suas propriedades relacionais e sua "plasticidade", quando se trata de auxiliar a compreender fenômenos e apreender objetos no campo das Ciências Sociais. Partindo do princípio de que, em Ciências Sociais, tudo é relacional, uma das principais possibilidades que surgem quando se vai operar com o escopo conceitual de autores como Pierre Bourdieu é a de tentar aplicar esses conceitos a conhecimentos e objetos de diversas áreas. Com essa finalidade, procuramos discorrer brevemente sobre algumas possibilidades da aplicação de tais conceitos em uma pesquisa educacional de caráter histórico.
Pierre Bourdieu é um autor cuja influência se alastrou por vários dos espaços disciplinares (e interdisciplinares) das Ciências Sociais. Quando se trata de realizar pesquisas em educação (principalmente na área de Sociologia da Educação), é comum a tentativa de operar com os conceitos de habitus e de campo como se fossem entidades distintas, estanques e incomunicáveis (NOGUEIRA, 2002), gerando desnaturações desses conceitos sem conseguir, no entanto, que, apesar dessas modificações, eles se prestem a analisar diferentes realidades sociais e temporais. Com o intuito de tentar evitar a reincidência nesse tipo de equívoco, procuramos verificar, de maneira atenta, quais são as possíveis conexões entre as dimensões relacionais dos conceitos de habitus e campo e a temporalidade histórica (DOSSE, 2003) à qual o objeto em que pretendemos concentrar nossos esforços heurísticos está vinculado. No entanto, como isso poderia ser feito? Para tentar responder a essa questão, recorremos à seguinte citação de Bourdieu:

[...] o inconsciente é a história - a história coletiva que produziu nossas categorias de pensamento, e a história individual por meio da qual elas nos foram inculcadas: por exemplo, é a história social das instituições de ensino (a mais banal e a mais ausente da história das idéias, tanto das filosóficas quanto das demais) e a história de nossas relações (esquecida ou recalcada) com estas instituições que podem nos oferecer algumas verdadeiras revelações sobre as estruturas objetivas e subjetivas (classificações, hierarquias, problemáticas, etc.) que, a despeito de nossa vontade, sempre orientam nosso pensamento. (BOURDIEU, 2003, p. 19). 
Conforme visto, o habitus possui muito mais de senso prático do que de cálculo racional, e esse senso permanece mais nos hábitos automáticos e nas condutas inconscientes do que na dimensão subjetiva racional. Tomando por princípio a idéia de que "o inconsciente é a história", uma das possibilidades que se abrem para operar com os conceitos de habitus e campo em uma pesquisa na área de História da Educação seria, justamente como indica Bourdieu, fazer um levantamento histórico social das instituições de ensino. Essa modalidade de pesquisas históricas pressuporia uma espécie de estudo pelos contrários (BACHELARD, 2004) como forma relacional de chegar a inferências sobre o habitus e o campo que constituem a realidade social (pertencente ao passado) analisada em uma pesquisa deste jaez. Tal estudo pelos contrários se daria com o intuito de, ao estudar o processo de formação do habitus de alguns agentes pertencentes a tais instituições (algo parecido com as reflexões que Pierre Bourdieu desenvolve em sua obra intitulada Esboço de auto-análise), realizar um estudo do campo sobre quem formou e conformou as instituições escolares em que o sujeito atuou e que foram influentes em sua trajetória (mas também foram por ele influenciadas), o que tornaria possível reconstruir historicamente, pela via da pesquisa das trajetórias individuais, traços da dinâmica de campos sociais que configuraram instituições escolares em momentos de tempo distintos do atual. Igualmente, ao se avaliar o campo (ou os campos) em que se situavam determinadas instituições escolares à época escolhidas como elemento de periodização do estudo, se poder-seia, por uma análise aprofundada das leis desse(s) campo (s) e da illusio envolvida nas disputas pelo poder, realizar inferências a respeito dos padrões de formação dos habitus dos sujeitos nelas pre- sentes e, assim, reconstruir (ao menos em parte) elementos da história social das instituições escolares concernentes aos sujeitos nelas presentes e de suas relações com o campo e as estruturas sociais vinculadas à época estudada.

\section{Considerações finais}

À guisa de conclusão, podemos dizer que trabalhar conceitualmente com um autor rico, do ponto de vista teórico, como Pierre Bourdieu não é tarefa das mais fáceis. Neste breve ensaio, buscamos identificar uma das possíveis maneiras de trabalhar com esse autor em um campo disciplinar distinto do da Sociologia (o que, ao que tudo indica, eleva o grau de dificuldade presente nessa tarefa, mas não a torna menos interessante), mas consciente de duas limitações presentes nessa empreitada: a) a perspectiva bourdieuniana pressupõe um trabalho de relacionamento "instantâneo" entre a teoria e a empiria, ao mesmo tempo em que requer muitas comparações e testagens duradouras no que se refere aos objetos estudados, o que ainda não se mostra possível em um veio ainda nascente de pesquisas encetadas sob tal perspectiva; b) as limitações de ordem prática, como dificuldades de financiamento e a necessidade de uma dedicação tendente à exclusividade, o que certamente oferece alguns obstáculos para a desenvoltura de um trabalho contínuo de análise como o que apresentamos.

Em razão dessas limitações, torna-se importante ressaltar que pretendemos apenas indicar algumas das possibilidades da utilização desses dois conceitos analíticos bourdieunianos, atentando, porém, para o fato de que, nesse momento, a maior contribuição (e não consideramos que 
seja pequena ou de pouca valia por isso) que esses conceitos nos trouxeram foi auxiliar no direcionamento que devemos dar a algumas análises no decorrer das pesquisas em história da Educação, para evitar a realização de um estudo histórico desconectado das realidades sociais que configuram a história das instituições escolares.

Finalizando, podemos dizer, sem dúvida alguma, que o trabalho conceitual com esse autor, se desenvolvido com rigor e atenção, constitui arcabouço teórico-metodológico de enorme valia para autores de vários campos das Ciências Sociais, não se circunscrevendo somente ao campo da Sociologia, desde que compreendidos e observados os fundamentos de sua análise relacional do mundo social.

\section{The applicability of the bourdieunian concepts of babitus and field in a search in the area of the history of education}

In this work we intend to carry out an analysis of the operationalization of two concepts created by Pierre Bourdieu, with wide spectrum range for the research work in Social Sciences (BOURDIEU, 2004). The concepts in question are of habitus and field, conceived by the eminent French sociologist as true operational tools of support to the research work. In this direction, we shall mention our intention in this essay of exploring some of the possibilities of use of these concepts in a historical research, considering that its versatility in terms of conceptual wealth surpasses the limits of sociology, being able also to be used in other fields of social sciences, as history, and, more necessarily, the history of education. The present work is composed of the following parts: a) brief explanation regarding the concepts of habitus and field; b) the applicabil- ity of the concepts in a research in the field of the history of education; c) final considerations.

Key words: Field. Habitus.

History of education. Research.

Sociology of Education.

\section{Nota}

1 Como exemplo, aplicando o conceito de campo ao estudo dos campos universitários, poder-se-ia dizer, trabalhando em uma perspectiva bourdieuniana, que o campo universitário composto das instituições de ensino superior do Rio de Janeiro não obedeceria à dinâmica do campo universitário formado pelas instituições de ensino superior parisiense, ainda que em muitos casos por um efeito de homologia estrutural, algumas dessas relações entre agentes e estruturas fossem assaz semelhantes.

\section{Referências}

\section{BACHELARD, G. Ensaio sobre o conbecimento}

aproximado. Rio de Janeiro: Contraponto, 2004.

BOURDIEU, P. A gênese dos conceitos de habitus e campo. In: BOURDIEU, P. O poder simbólico. Rio de Janeiro: Bertrand Brasil, 2001. p. 59-74.

Fieldwork in Philosophy. In: BOURDIEU, P. Coisas ditas. São Paulo: Brasiliense, 2004. p. 15-48.

Espaço social e espaço simbólico. In:

BOURDIEU, P. Razões práticas: sobre a teoria da ação. Campinas: Papirus, 2003. p. 13 - 28.

Meditações pascalianas. Rio de Janeiro:

Bertrand Brasil, 2001.

DOSSE, F. História. Bauru: EDUSC, 2003.

NOGUEIRA, C. M. A sociologia da educação de Pierre Bourdieu: limites e contradições. Educação e Sociedade, ano XXIII, n. 78, p.15 - 37, abr. 2002. 
PASCAL, B. Pensamentos. São Paulo: Martin Claret, 2000.

REVEL, J. Microanálise e construção do social. In:

REVEL, J. (Org.). Jogos de escalas. Rio de Janeiro: FGV, 2001.
SETTON, M. G. J. A teoria do habitus em Pierre Bourdieu: uma leitura contemporânea. Revista Brasileira de Educação, São Paulo, v. 20, p. 60-70, maio/jun./jul./ago. 2002. recebido em 25 jul. 2007 / aprovado em 10 out. 2008

Para referenciar este texto:

SANTOS, P. S. M. B. dos. A aplicabilidade dos conceitos bourdieunianos de habitus e campo em uma pesquisa na área da História da Educação. Dialogia, São Paulo, v. 6, p. XX-XX, 2007. 